\title{
Implicit Discount Rates and the Purchase of Untried, Energy-Saving Durable Goods
}

\author{
DOUGLAS A. HOUSTON*
}

\begin{abstract}
Many consumers appear to rationally calculate the net worth of a household investment, but a substantial minority may lack the skills or alertness to perceive an investment opportunity and initiate analysis. Intentions to engage in complementary activities play an important role in the investment decision.
\end{abstract}

$\mathrm{W}$ hy do some consumers require 50 percent or greater returns on household investments? Why do other consumers reject investments yielding 50 percent or greater returns? Based on empirical analyses of consumer investments in energy-using durable goods, some economists have argued that consumers become confused and hesitant when monetary paybacks stretch over many years; they may be unable to choose rationally among investment options. Gately (1980) found that extremely high discount rates were applied by consumers in the purchase of an energy-using durable. Hausman (1979) estimated that very high implicit discount rates were used by lower income consumers. Hausman argued that lower income consumers were less educated and may have suffered (relative to more educated individuals) from a defective "telescopic facility" - an inability to measure correctly the net worth of investments in durables.

The purpose of this paper is to examine the factors which influence a household's investment in an untried, energysaving durable good. At one level, we seek to test the hypothesis that a household investment decision is rational-that is, based upon an analysis of expected costs and returns for an entire investment program. It would be proper in a rational investment analysis to include all expected, user-borne costs of initial planning, purchase, use, and resale or disposal. These costs (hereafter termed program costs) are frequently ignored in empirical analyses, but if program costs vary substantially across the investing household population, we should observe systematic, positive variations between individual discount rates and these additional costs. Higher discount rates would reduce the likelihood of investment. Because program costs are not directly observable, proxies are used in this study. For example, an index of prior experience with energy-saving activities and an index of intentions to engage in energysaving activities are employed in regression analysis; both

*Douglas A. Houston is Assistant Professor of Business Economics, School of Business, University of Kansas, Lawrence, KS 66045 . He thanks Bruce Jaffee for helpful comments on previous drafts of this paper. are considered to be related to particular aspects of expected costs. Other explanatory variables considered are: household income, number of individuals in the family, housing type, housing age, and household square footage.

At another level, persistent errors in judgment may be a significant factor in the behavior of many potential investors, as Hausman suggests-that is, a clear perception of investment opportunity may be lacking in some respondents (Kirzner 1973). These households may, more frequently than others, refuse to consider investments, in spite of the size of the return. A second purpose of the study is to analyze the differences in characteristics between unresponsive households and those that perceived more clearly an opportunity to invest.

The empirical investigation is based on data acquired from a mail survey of approximately 3,000 households. Data were obtained on various aspects of energy use and a number of demographic characteristics of the households. Households also responded to a hypothetical question of the necessary annual cost savings required to cause them to purchase an energy-saving durable good with unspecified characteristics. Initial purchase and installation price for the long-lived device were given to the respondents. By use of qualitative choice models, we examined (1) the relationship between a set of explanatory variables and the minimal acceptable return on the investment, and (2) the factors which influence a respondent to avoid considering an investment proposal, regardless of potential return.

A number of caveats are in order. First, for the purpose of this paper, we follow Becker's (1965) model of the household as a single economic unit with shared consumption and production. While criticisms of the "new home economics" abound (Ferber and Birnbaum 1977; Lancaster 1975; Willis 1973), this paper focuses on the issue of the investment decision of the household as a singular decisionmaking unit. To the extent that a household utility function is inappropriate, the results of this paper should be tempered by judgment. Second, the study does not contain all economic and demographic variables likely to affect the investment decision, and does not contain psychological information about respondents. For these reasons, as well as 
the possibility of some nonrational behavior, there is considerable unexplained variance in the estimations. Third, the investment proposal is hypothetical, so we cannot be confident that responses would be identical for an actual investment. Last, the paper does not attempt to explain the complex decision process by which the investment is analyzed. Therefore, we cannot determine how the investment decision is reached, but can only provide some evidence about the economic rationality of that decision process.

\section{THE INVESTMENT DECISION MODEL}

\section{Framework of the Problem}

The respondents in our study considered the following question: ${ }^{1}$

If an energy-saving device, with a very long useful life, could be purchased and installed in your home for $\$ 100$, approximately how much would you have to save in energy costs each year before you would install the device?

Respondents were given seven response options: (1) less than $\$ 10$ per year; (2) $\$ 10-\$ 20$ per year; (3) $\$ 21-\$ 30$ per year; (4) $\$ 31-\$ 40$ per year; (5) $\$ 41-\$ 50$ per year; (6) more than $\$ 50$ per year; and (7) don't know or uncertain.

Faced with such a cost-saving investment choice, many consumers were unclear about how to proceed. Quite likely, simple rules of thumb were applied to the problem. In selecting a particular return (or choosing not to respond), the decision, to be rational, must incorporate information about expected costs and returns. In textbook examples of investment analysis, the costs, returns, and degree of uncertainty are generally treated as a manageable, mathematical exercise. On the surface, the question posed about the energy-saving device may appear to be easily approached by a mathematical, cost-benefit, present-value analysis. Given that framework, the choice variable then is the net implicit discount rate.

We hypothesize that the information provided to the consumer in the investment question is insufficient to allow a complete analysis, even though the question clearly states annualized cost savings. First, each consumer, prior to committing to an investment, has an understanding of his or her skillfulness and knowledge in undertaking the investment program. The user-borne program costs-cost of analysis, cost of household labor in implementation, and costs associated with resale or disposal-should be considered by the rational investor; these program costs will, in general, vary among households. Second, the device's potential complementarity (or substitutability) with existing household energy stocks may alter the value of the device and the chosen discount rate. These factors would be estimated by the rational investor and included in the costbenefit analysis.

For the energy-saving investment proposal investigated

\footnotetext{
${ }^{\prime}$ Respondents are individual households in southern and central Indiana The details of the data collection method, selection of respondents, and characteristics of the sample are presented later in the paper.
}

in this paper, the various expected costs and values through time (both monetary and nonpecuniary) can be summarized in the choice by the consumer of a minimally acceptable annualized monetary cost savings. That choice implies the existence of a gross discount rate (GDR) used in the decision. The term "gross" is employed to emphasize that the return selected by respondents may be based on a number of additional program costs and savings beyond those stated on the questionnaire.

\section{Interpretation of the Response to the Investment Question}

Because the hypothetical investment question resulted in no actual costs or reward to the respondent, a potential problem arises in interpretation of the gross discount rate responses. Are we examining the decision that would be made in real life? A judgment is necessarily speculative. While the study could have been performed for actual rather than hypothetical investment behavior, there are two major problems with the former approach. First, the model developed in this paper requires detailed information about households that rarely can be obtained for households that have all considered the same investment. Second, it is the expected cost savings that are important to the investment decision rather than realized savings. The study uses the hypothetical question to achieve the notion of expected conditions, but it may not be fully representative of actual investment behavior, since no monetary penalty or reward results from the decision.

There is evidence that many respondents answered carefully. At the end of the completed survey, in space provided for comments, many individuals indicated their concerns about the survey investment question. Some added assumptions, such as the high probability that their household could not achieve the stated savings due to current low energy usage. Many expressed skepticism that any energy device truly achieves its stated cost savings after all cost factors are considered. ${ }^{2}$ Such comments suggest that many respondents did not take the explicit cost-saving statement as the complete picture. Instead, they may have modified their investment analysis according to individual perceptions of other expected program costs and savings.

A few consumers seemed to believe that the investment would in some way lead to loss of a currently useful household durable-i.e., that the energy-saving device was a replacement rather than an add-on item. Such an interpretation was not intended by the survey team. Under replacement conditions, a rational investor would reduce the net present value obtained from the new investment by the remaining present value of returns from the existing durable to be replaced, less any scrap value. To the extent that

\footnotetext{
${ }^{2}$ Skepticism about payoffs from household energy investments may be a reasonable response, if prior information tended to be overly optimistic about expected savings. For example, the effect of installing ceiling insulation on energy usage has tended to be overestimated by both marketers and government agencies. See Consumer Reports (1978).
} 
respondents interpreted the investment as a replacement rather than as a new durable, the required return on investment and the observed implicit discount rate were increased.

Some respondents indicated confusion about how to proceed in determining the "appropriate" response. Others indicated that insufficient information was provided to allow an answer they could support. These and other respondents who offered no explanation of how they answered may have been perplexed by the question. Confusing conditions are generally present (often in much greater degree) in a consumer's purchase decision about any untried durable good. Clearly, more precise and extensive information would have made the task easier, but it also would have altered an important, interesting aspect of the investment problem. Many consumers, facing an unusual investment proposal, may lack the alertness to conceptualize clearly the costs and benefits. These confused respondents affect our analysis in two ways. First, many individuals (approximately one-third of the sample) responded to the investment proposal with "don't know or uncertain." Second, the nonrational selection of positive returns by confused individuals is reflected in the weakening of the economic model of implicit discount rate, reducing its explanatory power.

A flow chart of the decision process is shown in the Figure. We expect respondents who have the alertness and analytic ability to select a positive savings necessary to induce investment. In general, these individuals rationally augment the questionnaire's statement of costs and savings with other user-borne program costs prior to deciding on a necessary return. Although it is possible for a rational individual to select a "don't know or uncertain" response, the ability to select the highest return (open-ended upward) should provide an appropriate response for individuals who are highly uncertain about costs or expect to bear high program costs. ${ }^{3}$ The response of "don't know or uncertain" is generally nonrational. Many individuals selecting it lack a decision rule (rule of thumb) to guide them in comprehending the data. Unfortunately, some of these individuals may simply randomly select a positive return, thus weakening the linkage of explanatory factors to the discount rate in estimation.

We treated the two groups (positive response or " don't know" response) separately in empirical analyses. Those answering with a positive savings requirement were examined in a tobit regression model of the discount rate level. "Don't know or uncertain" answers were examined in a probit regression of the choice between the "don't know" versus a positive return response.

\footnotetext{
3Some "don't know or uncertain" responses, however, can be economically rational. If a respondent expects that the cost of trying to understand the question sufficiently well to answer thoughtfully is greater than the value of that effort, he may rationally choose a "don't know or uncertain", answer. Yet many who would fit into this category may have applied a similar logic to the entire questionnaire and are therefore nonrespondents.
}

\section{DATA SOURCE}

All information used in the estimations was taken from a mail survey of individual households. Approximately 3,000 residential households serviced by 18 rural electric membership cooperatives (REMCs) in southern and central Indiana were surveyed. The sample was selected from the records of the cooperatives by a random sampling technique. To focus upon residential customers having similar opportunities to apply an energy-saving device to their household operations, those households that were engaged in farming, that did not own their dwelling, or that lived in the unit for only part of the year were eliminated from the analysis. Census data for housing, population, and income were used to compare the respondents with the regional population. The respondents were found to be representative.

The questionnaire included 35 items related to various aspects of energy consumption in the home, appliance ownership and use, measures of past and intended energy conservation measures, selected demographic characteristics of the household, and an energy-saving investment proposal. The questionnaire was mailed in the summer of 1979 and was returned, fully completed, by 83 percent of the households.

The high response rate was obtained without followup contact after the initial mailing. Individual users own the cooperatives and therefore may have felt a commitment to respond to the survey. Prior to the mailing of the survey, the general manager of each cooperative sent a letter to each selected household in his or her cooperative requesting assistance and stressing the importance of the survey to the cooperative. Enclosed with each mailed survey was a dollar bill that the recipient was told to keep, regardless of whether the 35-question survey was completed. At a minimum, the dollar bill may have prompted a fairly quick response. Interestingly, many people who did not complete the questionnaire returned the dollar bill.

Restricting the study to households occupied for the full year and households without significant farm-related operations reduced the number of observations to 1,081 . Of these, 725 responded to the investment question with a positive return and 356 answered "don't know or uncertain."

There are clearly some problems of measurement with respect to household square footage, annual income, and the listing of past and intended conservation efforts. For example, individuals usually have an imprecise notion of the heated square footage in their homes. These problems are largely a shortcoming of the survey form of information gathering.

\section{THE EMPIRICAL STUDY}

\section{Tobit Regression Analysis}

Based on positive saving responses to the investment question, a gross implicit discount rate $(G D R)$ was calcu- 
FIGURE

THE INVESTMENT PROBLEM

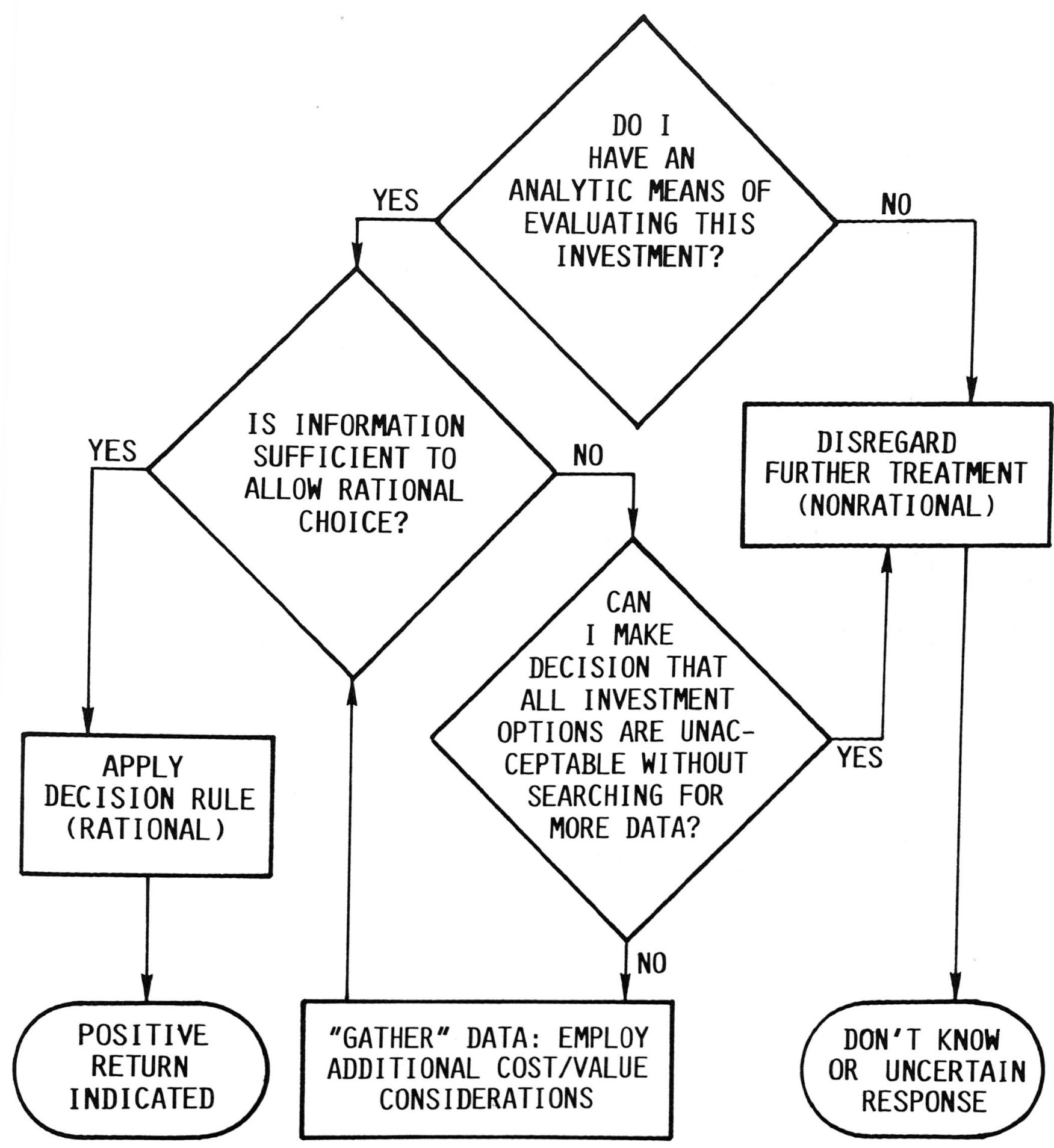


lated for each respondent. The discount rates are directly calculated on the assumption that the returns per year are perpetual. ${ }^{4}$ The perpetual rates are $0,10,20,30,40$, and 50 percent for mean annual cost saving responses of $\$ 0$, $\$ 10, \$ 20, \$ 30, \$ 40$, and $\$ 50$, respectively.

The multivariate regression model, $G D R=X B$, where $X$ is a matrix of explanatory variable observations and $B$ is the vector of coefficients, can be estimated by OLS. However, OLS will yield biased estimators if there are many observations clustered at the limiting value of the dependent variable (a response of 50 percent). This information can be applied to the estimation of the discount rate. ${ }^{5} \mathrm{~A}$ tobit model is useful in dealing with such a truncated, dependent variable in multivariate regression analysis (Tobin 1958).

Tobit is a hybrid of probit and multiple regression. It yields answers to two questions in this study: (1) the probability of a participant responding that the stated payoffs were sufficient to warrant investment, and (2) the necessary discount rate to entice investment. In using this procedure, an index, $I_{i}$, is estimated which is linearly dependent upon a set of independent variables. $I_{i}=X A$, where $I$ is unbounded and $A$ is a vector of normalized coefficients. Each observation of the dependent variable, $G D R_{i}$, is a function of the same explanatory variable set, $X$, through the $I$ variable and a critical value of the index, $I^{*}$. If the upper bound, $I^{*}$, is greater than $I_{i}$, then $G D R_{i}$ is the difference between $I_{i}$ and the critical $I^{*}$.

The probability that $G D R$ is less than the limit can be examined for any observation by using the standard normal cumulative distribution to transform $\hat{I}_{i}$ into probabilities. The normalized coefficients in the model then can be transformed to regression coefficients by multiplying by the standard error of estimate. Hypothesis testing can be performed using the asymptotic standard errors or likelihood ratio tests.

Those households that answered "don't know or uncertain' (approximately one-third of the sample) were excluded from the analysis of the discount rate level. Because the investment question allowed any level of positive savings to be indicated through a response of " $\$ 50$ or more," the failure to make a positive response may indicate that the "don't know or uncertain" respondents were unable to formulate the problem sufficiently well to perceive an opportunity. Thus cost savings on the investment may be meaningless to them. Using a probit model, we examined the factors that affect the probability of a "don't know" response.

\footnotetext{
${ }^{4}$ Choosing a different investment life will slightly alter the discount rates, but the estimated coefficients do not appear sensitive. When a $20-$ year life is used, very few differences emerge in regression results.

${ }^{5}$ Regardless of the regression model used, the results are robust, providing similar regression coefficient values and levels of statistical significance for the explanatory variables. Another regression model that could be used, in lieu of tobit, is an extension of the dichotomous probit model which allows a categorical, discontinuous variable (see McKelvey and Zavoina 1975).
}

\section{The Empirical Model of the Discount Rate}

The consumer's choice of a minimum return on investment is empirically examined with a disaggregate tobit model:

$$
\begin{aligned}
G D R= & B_{0}+B_{1} E \bar{X} P+B_{2} I \bar{N} T \\
& +B_{3} I N C+B_{4} H \bar{S} F+B_{5} N U M \\
& +B_{6} D T+ \\
+ & +B_{7} D A G
\end{aligned}
$$

where:
$G D R=$ the gross, implicit discount rate, implicitly se- lected by the respondent through his or her choice of a minimum annual savings from the investment
$E X P=$ a variable of major household energy conser- vation measures performed within the last 24 months; 11 options were equally weighted in an index (see Appendix for details)
$I N T=$ a variable of stated intentions to invest in en- ergy conserving measures in the coming 12 months; 11 options were equally weighted in an index (see Appendix for details)
$I N C=$ annual income for the household
$H S F=$ heated square footage of the household
$N U M=$ number of individuals living full-time in the household
$D T Y=$ dummy variable for housing type $(1=$ mobile home; 0 = conventional)
$D A G=$ dummy variable for housing construction date ( $1=$ pre-1974; $0=1974$ or newer)

In estimating Equation 1, we seek to explain the relationship between the level of the discount rate for the investment and a set of explanatory economic and demographic variables. The expected signs of the regression coefficients are displayed above the variables in the equation.

\section{Testable Hypotheses}

The tobit model of the gross discount rate level (Equation 1) provides the basis for a number of testable hypotheses. In general, to be consistent with economically rational behavior, the model should support a positive relationship between higher expected program costs to the investor and the required return on investment (indicated by $G D R$ ). As discussed, many expected user-borne costs may be excluded from the explicit statements of costs and savings in the mail survey. Factors indicating higher program costs to a consumer (compared to others in the sample) should push up the individual's discount rate. Conversely, factors indicating reduced relative expected program costs should reduce the discount rate necessary to make the investment worthwhile. The variables included in Equation 1 are briefly discussed in what follows. 
1. Greater experience (EXP) and more planned actions for saving energy (INT) should negatively affect the discount rate (GDR). Tversky and Kahneman (1973) and Kahneman and Tversky (1972) have shown that as events become harder for an individual to picture, s/he will consider the events less likely to occur. Thus, past experience with investment analysis for similar types of durables or the present, ongoing consideration of similar investments should make a consumer more willing to engage in analysis. Prior experience with similar investments may alter perception of investing skills. For an investment in a technology with many unclear or unstated attributes, a consumer's dependence on prior experience with investment goods sharing similar general characteristics is hypothesized to reduce the expected cost from implementation of an investment program. For example, the recent purchase and installation of insulation or a heating unit may increase a consumer's confidence that s/he can easily incorporate more improvements into the household.

Where intentions to engage in planned energy-saving activities are strong, there may be expected cost savings associated with implementing and managing a number of complementary investments. With many similar investments expected, a consumer is likely to view the costs of adding another as low; an investment in learning how to use such durables has already been "sunk." The intention variable also may be positively correlated with consumer attitudes favoring conservation as a desired end in itself. If so, a consumer responding with high numbers for the INT variable would require a smaller monetary payback. It should be emphasized, however, that the intentions variable is not an attempt to directly measure attitudes.

Because the two variables, EXP and INT, are indices formed as equally weighted summations of 11 different possible conservation actions, the reliability of both indices should be examined. An internal consistency procedure, the Cronbach alpha coefficient, was employed to examine reliability. The coefficients for EXP and INT were 0.65 and 0.68 , respectively. While there is no statistical test for acceptance or rejection of the value, alpha values of this size give some degree of confidence that the indices are reliable (Nunnally 1978, pp. 229-230).

2. Higher household income (INC) should negatively affect the discount rate. There are several effects of income upon the discount rate level. First, income may be positively correlated with educational level. Individuals with more education may be more capable of understanding the investment proposal than those with less education. If low-income families recognize a high probability of their making large errors, then they rationally choose high rates of return to compensate for the risk. ${ }^{6}$ Second, as Hausman

\footnotetext{
${ }^{6}$ Lower income families also may tend to ignore the investment and respond "don't know or uncertain.", These responses are not included in the analysis of positive discount rates; they are examined in a following section.
}

(1979) observes, as income and marginal tax rate rise, some added savings accrue to the investor in consumer durables, reducing the needed return.

The first two effects (suggesting a negative income-to$G D R$ relationship) may be countered by the incentive for higher income families to increase work outside the home; this statement presumes that a higher income level is indicative of increased labor earning power. Substitution away from household production activities when real wages rise has been observed, among others, by Menefee (1982). The respondents' perceptions of the complementarity of labor input to the operation of the device is unknown. If, in fact, the capital services from the investment are perceived as substitutes for labor, then additional implicit cost saving would occur, and the gross implicit discount rate would be affected negatively. Although there may be some varying directions of influence, the overall effect of income on the discount rate is predicted to be negative.

3. Greater household size, measured in square footage of heated dwelling space (HSF), should negatively affect the discount rate. For household square footage to directly reduce $G D R$, the respondent must expect cost savings (beyond the direct functioning of the device) from a larger household. Household size, for example, may be positively correlated with heating and cooling system stocks and other energy-using capital. If a respondent expects scale economies with respect to the energy-using household capital, then additional savings may be anticipated beyond those stated for the device.

However, household size may be positively correlated with wealth. If greater wealth reduces the overall savings rate of consumers (see Ferber 1973), the HSF variable may be acting, in part, to reduce investments in a household durable. Other lines of causality could be presented. A spurious cause of a positive relationship between HSF and $G D R$ is due to the correlation of $H S F$ with income. The simple correlation between the two variables is +0.46 . Therefore, income and household square footage effects may best be interpreted jointly.

Additional dummy variables for mobile home versus conventional home (DTY) and for older (pre-1974) homes $(D A G)$ were included in the empirical model to control for variability due to structural differences in dwellings.

4. As the number of household members (NUM) increases, the required discount rate should increase. There are two influences to consider. First, as the number of individuals under one roof increases, the income available to each falls. There is considerable evidence that lower per capita income leads to a decrease in the short-run savingsto-consumption ratio (Ferber 1973). Assuming the average household member's well-being is considered in spending decisions, as income falls, an increase in the required discount rate on any given investment is expected.

The second influence concerns the complementarity or substitutability of household labor for the capital services 
of the proposed investment. Labor complementarity suggests a downward revision in the stated cost savings from the device. However, if the new capital is expected to be a substitute for some household labor, then the cost savings may be enhanced. The true relationship is not clear. Another problem of inferring expected labor cost for the number of individuals in the household is the unknown quality of the labor. For example, small children may be unacceptable "workers." On balance, the per capita income effect is expected to be larger than any effects of labor in household production, and the expected sign of $N U M$ is positive.

To summarize, the expected effects of explanatory variables upon the household's selection of a discount rate are:

- Greater income or greater household square footage is expected to reduce an individual household's discount rate. Because of collinearity between these two explanatory variables, individual effects on $G D R$ may be obscured and only a joint interpretation of effect may be reasonable.

- Both experience with energy-conserving activities and intentions to engage in such activities are hypothesized to reduce the discount rate.

- More household members are expected to increase the discount rate.

Relationships between explanatory variables and the level of the discount rate (dependent variable) can be interpreted as follows:

- The higher the discount rate, the less likely that a similar real investment will be undertaken.

- Thus any variable that positively (negatively) affects the discount rate will reduce (increase) the likelihood of a household undertaking energy-conserving investments.

\section{Results of the Discount Rate Estimation}

Because the cost saving response is truncated ( $\$ 50$ or more), a tobit model was used in estimating the discount rate with the limiting value of the discount rate at 50 percent. At the mean of continuous variables and modal values of the dummies, the probability of a nonlimit observation (positive return less than 50 percent) is 87.9 percent; the observed frequency is 87.7 percent. Table 1 shows the normalized coefficients, $t$-ratios, estimated regression coefficients, and the elasticities at the means of continuous variables. The regression coefficients and elasticities apply to the relationship between the explanatory variables and the level of the gross discount rate, given that GDR is a nonlimit observation. Summary statistics for the explanatory variables are shown in Table 2 (left columns), and the simple correlation coefficient matrix is shown in the upper section of Table 3 .

Changes in the level of the discount rate are most sensitive to the household square footage (HSF). Also important in terms of the percentage change in the discount rate level resulting from a percent change in an explanatory variable (elasticity) are number of family members (NUM) and intentions to conserve (INT):
TABLE 1

RESULTS OF TOBIT ANALYSIS ${ }^{a}$

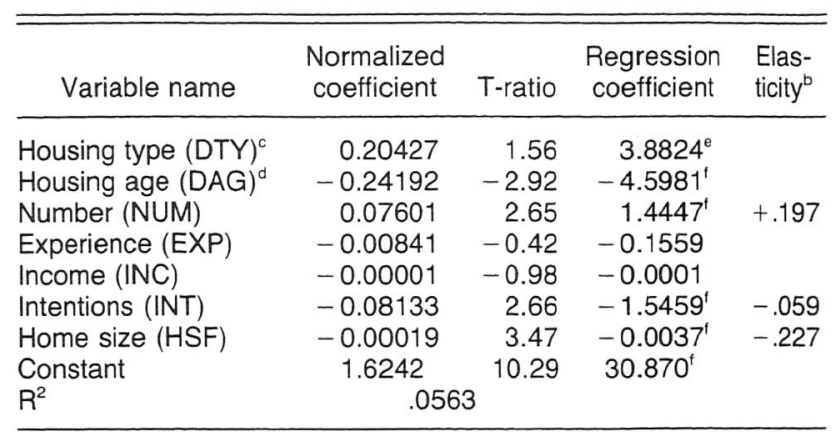

${ }^{\mathrm{a} G i v e n}$ nonlimit observation; upper limit response $=50$ percent. Dependent variable $=$ gross, implicit discount rate.

${ }^{b}$ Elasticities calculated at mean values (percentage change in size of discount rate for small percentage change in explanatory variable, given nonlimit observation).

'Dummy variable for housing type ( $1=$ mobile home; $0=$ conventional).

${ }^{d}$ Dummy variable for housing age ( $1=$ pre-1974; $0=1974$ or newer).

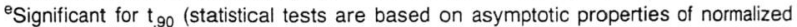
coefficients).

'Significant for t.99. $^{\text {t. }}$

\begin{tabular}{lc} 
& Elasticity \\
\cline { 2 - 2 } Household square footage & -.227 \\
Number in family & +.197 \\
Intentions to conserve & -.059
\end{tabular}

Although these three variables act in accord with the hypotheses, income, surprisingly, does not. The coefficient is negative but insignificant. There are a number of possible explanations for the result. First, the high correlation between income and household square footage $(+0.46)$ makes it difficult to interpret the two variables independently. Thus, the testing of independent effects on the discount rate from each of these variables may not be meaningful. Second, it may be that the various counterbalancing influences of the income variable previously discussed weakens the linkage to the discount rate. Last, the overall magnitude of the effect of income on the discount rate may be slight, making findings of statistical significance difficult to obtain. Interestingly, the role of income is greatly expanded in explaining the choice of a "don't know or uncertain" response, suggesting that at this more elementary level of choice, income plays a different role. This is discussed in the following section.

For energy-saving durables, a dampening influence on investment may result from a trend decline in the size of housing units. For example, the construction of smaller new homes may lead to a decline in the acceptance of new energy-saving investments. A countering effect may be a decline in the average family size-a trend which would act to lower the required discount rate and increase the probability of investment.

Although household size and number in the family are important variables, the intentions to engage in conserving activities (INT) may have a more important short-term influence on energy-saving investments. Household square 
TABLE 2

SUMMARY STATISTICS OF VARIABLES

\begin{tabular}{|c|c|c|c|c|}
\hline \multirow[b]{2}{*}{ Variable name } & \multicolumn{2}{|c|}{$\begin{array}{l}\text { Positive savings responses only } \\
\text { (725 observations) }\end{array}$} & \multicolumn{2}{|c|}{$\begin{array}{c}\text { "Don't know or uncertain" responses } \\
\text { (356 observations) }\end{array}$} \\
\hline & Mean & $\begin{array}{l}\text { Standard } \\
\text { deviation }\end{array}$ & Mean & $\begin{array}{l}\text { Standard } \\
\text { deviation }\end{array}$ \\
\hline Housing type (DTY)a & 0.10897 & 0.31181 & 0.17697 & 0.38218 \\
\hline Housing age (DAG) & 0.67724 & 0.46785 & 0.80337 & 0.39801 \\
\hline Number (NUM) & 3.2938 & 1.3748 & 3.0758 & 1.5771 \\
\hline Experience (EXP) & 1.9117 & 1.9032 & 1.5112 & 1.8877 \\
\hline Income (INC) & 19,612 & 9,863 & 12,969 & 8,781 \\
\hline Intentions (INT) & 0.92690 & 1.2411 & .5787 & 1.0546 \\
\hline Home size (HSF) & $1,485.7$ & 801.82 & $1,032.2$ & 752.18 \\
\hline
\end{tabular}

aDummy variable for housing type ( $1=$ mobile home; $0=$ conventional)

${ }^{b}$ Dummy variable for housing age ( $1=$ pre-1974; $0=1974$ or newer $)$.

footage, income, and number of family members are "stock" variables 7 and generally change quite slowly. On the other hand, large percentage changes in the intentions index are not improbable when the current level of intentions is low. For example, when the current intentions index is at 1 (activity), an increase by just 1 in intended activities would decrease the estimated discount rate from 22.2 to 20.9 percent in our model. To obtain a like change in the discount rate, mean family size would have to rise from 3.29 to 4.27 members. Because income and household square footage are highly correlated, an individual variable interpretation may be impreper. If considered jointly, income and household square footage still must rise far above normal trend to have the impact of a 1-unit increase in the intentions index. Promoting the concept of energy-conserving activities may be one way of altering the intentions of consumers to perform these activities. Thus successful promotions that substantially increase intentions should have a large influence on the actual acceptance rate of untried, energy-saving durable goods.

The hypothesized negative effect of the experience variable on the discount rate was not observed to be statistically significant. Experience and intentions are not necessarily positively linked; each may play a different role in the model. The simple correlation coefficient in this sample is +0.008 . Correlation could be negative if, for example, there were a major revision in consumer plans. The role of experience in providing assurance to an individual that $\mathrm{s} / \mathrm{he}$ has some basic competency in an investment area may be important in explaining the decision to examine an investment proposal on economic grounds. That subject is discussed in the next section.

Whether housing is mobile home or conventional (DTY) is statistically significant at the 90-percent confidence interval. The positive sign of DTY may be influenced by collinearity with household square footage $(H S F)$. The sim-

\footnotetext{
${ }^{7}$ Income may be considered as a stock (of wealth) if it is interpreted as a proxy for permanent income.
}

ple correlation coefficient of HSF to DTY is -0.325 . Surprisingly, $D A G$, the dummy on housing age $(1=$ pre-1974 construction), had a negative effect on the discount rate. An explanation of this result is not obvious. One line of reasoning is that older housing units are on average in poorer repair so that the probability of an energy-saving device achieving claimed results may be considered high.

The mean observed discount rate of 22.5 percent is not unusually high for an investment in household durables. Hausman (1979), in a study of consumer purchases of energy-saving appliances, found a 26.4 percent mean level of the discount rate. He estimated much higher rates for low income levels and much lower rates for very high income levels. By contrast, our results do not suggest this linkage of the discount rate level to income. The discount rates, calculated by income ranges, are:

\begin{tabular}{lc}
\multicolumn{1}{c}{$\begin{array}{c}\text { Annual } \\
\text { income range }\end{array}$} & Discount rate \\
Under $\$ 5,000$ & $21.6 \%$ \\
$\$ 5,000-\$ 10,000$ & $25.4 \%$ \\
$\$ 10,001-\$ 15,000$ & $25.3 \%$ \\
$\$ 15,001-\$ 25,000$ & $23.0 \%$ \\
Over $\$ 25,000$ & $19.9 \%$
\end{tabular}

These results suggest that, once a consumer is willing to consider an investment in terms of expected costs and benefits, income may play a weak role in predicting the discount rate level and the consequent acceptance rate. In the next section, we examine the role of income in the decision not to attempt an economic appraisal of the investment.

\section{The "'Don't Know or Uncertain', Response}

Here we look briefly at the factors that may push a household respondent into the "don't know or uncertain" response on the investment question. We have argued previously that this response is, in general, made without consideration of either future costs or values surrounding the durable. A decision made without examining costs or benefits cannot be considered as rational investment anal- 
TABLE 3

SIMPLE CORRELATION COEFFICIENT MATRICES

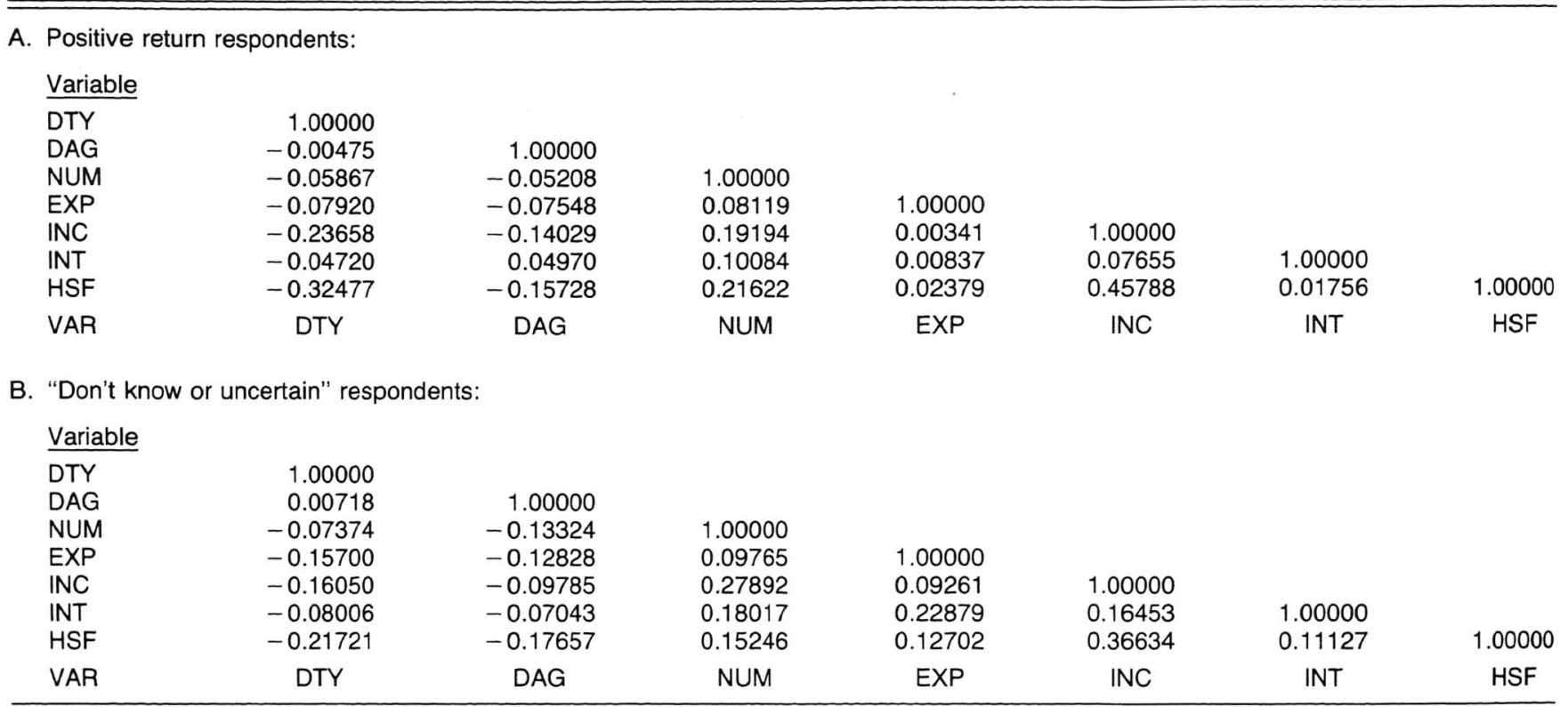

ysis. This assertion rests upon the option not chosen by the "don't know" respondents-i.e., to indicate the openended highest return on the investment; some positive return must be sufficient to induce investment for any rational individual.

The same set of explanatory variables from Equation 1 is used in a probit regression, where $1=$ "don't know or uncertain" response. Table 2 , in the far right columns, indicates means and standard deviations of each explanatory variable for the "don't know" respondents, and Table 3 shows the simple correlation coefficient matrix. The regression coefficient estimates and $t$-ratios are:

\begin{tabular}{|c|c|c|}
\hline Variable & Estimate & T-ratio \\
\hline DTY & -.06194 & -0.499 \\
\hline DAG & .20775 & 2.110 \\
\hline NUM & -.03736 & 1.269 \\
\hline EXP & -.04239 & -1.883 \\
\hline INC & -.00003 & -6.733 \\
\hline INT & -.11330 & -3.039 \\
\hline HSF & -.00026 & -4.117 \\
\hline Constant & .34647 & 2.139 \\
\hline $\mathrm{R}^{2}=$ & .1440 & \\
\hline
\end{tabular}

The largest difference between the probit model and the model of the discount rate level is the greater magnitude of the income effect in the probit analysis. In addition, experience is a statistically significant variable in the probit model. All other variables that were significant in the tobit analysis of the level of the discount rate remain so, and the size of the household square footage variable effect is increased. As discussed previously, consumers with low incomes may lack the tools to grasp the investment problem.
Thus income may act as a "filter," pushing such individuals into a "don't know" nonresponse. The relationship between income level and the probability of the "don't know," nonrational response is:

\begin{tabular}{|c|c|}
\hline Income level & $\begin{array}{l}\text { Probability of "don't know } \\
\text { or uncertain", response }\end{array}$ \\
\hline$\$ 5,000$ & $42.0 \%$ \\
\hline$\$ 10,000$ & $35.3 \%$ \\
\hline$\$ 15,000$ & $29.2 \%$ \\
\hline$\$ 20,000$ & $23.4 \%$ \\
\hline$\$ 25,000$ & $18.5 \%$ \\
\hline$\$ 35,000$ & $10.7 \%$ \\
\hline
\end{tabular}

High positive correlation between income and household square footage suggests the same warning as beforenamely, that the two variables may best be treated jointly. The magnitude of the combined effect of these two variables, moving in unison, should approximate the effects demonstrated in the tabular display just given.

Greater experience with energy-conserving activities tends to increase the probability that a positive savings response will be obtained from an individual. The fact that the experience variable (like income) is significant at this level of analysis but is not significant in the regression on the discount rate level is consistent with the following argument: (1) individuals' conceptual abilities are linked to prior experience as well as to income; (2) once this conceptual problem is overcome, the investment analysis hinges upon expected future benefits and costs, which are essentially unrelated to income or prior experience. While this line of reasoning has plausibility, there may be other arguments that could be offered. 


\section{Unexplained Variance}

The low $R^{2}$ values from the estimations suggests that these basic models may be weak in a number of ways. To obtain a measure of predictive validity, cross-validated correlations were obtained on the probit model. This was done by splitting the sample randomly into an estimation and a holdout sample. Regression parameters from the estimation sample were used to obtain predictions of the dependent variable in the holdout sample. The correlation of these predictions with the actual holdout values of the dependent variable was made. This procedure was then reversed, with the holdout sample becoming the estimation sample. For the overall sample estimation, the unadjusted $R^{2}$ is 0.144 . The two cross-validation correlations are 0.151 and 0.134 .

The low $R^{2}$ values reported for the estimated models do not signal the failure of the models. Part of the low explained variance in the analysis of the discount rate level may result from randomness of response by those who had no rational basis for choice. Undoubtedly, our models contain insufficient information to explain the initial responses to a tough investment decision. Personality characteristics, attitudes, and family life style-as well as additional economic considerations-may be quite important. Studies with more specific and extensive data on these factors should throw more light on the influences behind decisions about investments in untried durables. However, it is likely that low $R^{2}$ values would be obtained with a much richer data set. Questions that provide very little detailed information about a long-term activity and that require substantial conceptual and analytic ability will invariably puzzle prospective decision-makers. Our model only provides clues to some of the relevant factors behind investment behavior.

\section{SUMMARY}

In a mail survey, households were asked to choose either the minimal acceptable annual cost reduction on a longlived energy-saving device (given an initial purchase and installation price) or to choose not to respond by indicating "don't know or uncertain." We then sought to examine factors influencing the choices of households.

Factors related to expected cost and value influence the decisions of individuals who can conceptualize an investment problem. Generally, consumers acted as if there were additional costs beyond those stated in the survey question, and they consistently attempted to integrate the incremental costs into their investment decisions. In the study, this was reflected by lower individual discount rates for those bearing lower expected costs (or greater value) for the investment.

Factors that lower the discount rate increase the rate of acceptance of an untried durable good. Variables important to explaining the discount rate are: household square footage, number of family members, age of housing, and intentions to undertake energy-conserving activities. A major short-term decrease in the discount rate and increase in the acceptance rate for an investment is unlikely unless intentions are substantially revised upward. Unlike other variables in the model (such as income, family size, and household square footage), intentions are subject to larger and quicker adjustments that can rapidly alter the prospects for investment.

For individuals who do not have the conceptual tools to analyze the investment problem, a response to the investment question is, in general, nonrational (made without consideration of costs or benefits). The bulk of these individuals responded to the question with a "don't know or uncertain" response. Compared to those who went ahead and answered the investment question, the "don't know" respondents were characterized by lower income, smaller homes, larger families, less experience with energy-conserving activities, and lower intentions to engage in future energy-conserving activities.

The study did not find that consumers who participated in the survey by providing positive return responses were behaving irrationally. Although income was an important variable in predicting whether an individual would consider the investment analysis, it played no statistically significant role in explaining the level of the discount rate used by individuals. The mean discount rate observed in the study was 22.5 percent and does not vary significantly with income. This finding contrasts with earlier work by Hausman (1979), which found very high discount rates used by the poor.

\section{[Received June 1982. Revised June 1983.]}

\section{APPENDIX}

The indices of experience, EXP, and intentions, INT, were developed from each respondent's answers to the following question:

Check below those things which you or your landlord have done in the last twenty-four months (two years), if any, AND those which you or your landlord are definitely planning to do in the next twelve months, if any. Check ALL that apply.

Individuals were given 10 specific options of things they may have done or intended to do. For each, they could check "have done in the last 24 months," "definitely planning to do in the next 12 months," or both. The latter would be the appropriate response, for example, if the respondent had recently added ceiling insulation and intended to increase the thickness within the year. The 10 specific options were:

1. Add ceiling insulation

2. Add wall or floor insulation

3. Put insulation around a water heater

4. Install a clock thermostat

5. Purchase storm or insulated windows or doors

6. Adjust the usual temperature setting, either up in the summer or down in the winter 
7. Add attic or roof fans

8. Install an auxiliary heating unit using coal or wood

9. Add weather stripping or caulking around doors, windows, walls, or foundations

10. Purchase a more energy-efficient heating unit, air conditioner, or hot-water heater

An eleventh option was "other major energy conservation efforts (please specify)," and several blank lines followed for a response. Based on the number of checked responses out of a maximum of 11 for either past or intended action, the indices EXP and INT were developed. Thus, for example, $I N T=3$ would state that three of the possible actions listed were planned for the coming year.

\section{REFERENCES}

Becker, Gary S. (1965), "A Theory of the Allocation of Time,' Economic Journal, 75 (September), 493-517.

Consumer Reports (1978), "The Overselling of Insulation," 43 (February), 67-73.

Ferber, Marianne A. and Bonnie G. Birnbaum (1977), "The 'New Home Economics': Retrospects and Prospects," Journal of Consumer Research, 4 (June), 19-28.

Ferber, Robert (1973) 'CConsumer Economics, A Survey," Journal of Economic Literature, 11 (December), 1303-1342.

Gately, Dermot (1980), "Individual Discount Rates and the Purchase and Utilization of Energy-Using Durables: Comment,", The Bell Journal of Economics, 11 (Spring), 373-374.

Hausman, Jerry A. (1979), "Individual Discount Rates and the
Purchase and Utilization of Energy-Using Durables," The Bell Journal of Economics, 10 (Spring), 33-54.

Kahneman, Daniel, and Amos Tversky (1972), "Subjective Probability: A Judgment of Representatives,' Cognitive Psychology, 3 (July), 430-454.

Kirzner, Israel (1973), Competition and Entrepreneurship, Chicago: University of Chicago Press.

Lancaster, Kelvin (1975), "The Theory of Household Behavior: Some Foundations," Annals of Economics and Social Measurement, 4(1), 5-21.

Menefee, John A. (1982), "The Demand for Consumption Time: A Longitudinal Perspective," Journal of Consumer Research, 8 (March), 391-397.

McKelvey, Richard D. and William Zavoina (1975), "A Statistical Model for the Analysis of Ordinal Level Dependent Variables," Journal of Mathematical Sociology, 4(1), $103-120$

Nunnally, Jim C. (1978), Psychometric Theory, New York: McGraw-Hill.

Theil, Henry (1981), Principles of Econometrics, New York: John Wiley.

Tobin, James (1958), "Estimation of Relationships for Limited Dependent Variables," Econometrica, 26 (January), 24-36.

Tversky, Amos and Daniel Kahneman (1973) "Availability: A Heuristic for Judging Frequency and Probability,' Cognitive Psychology, 5 (April), 207-232.

Willis, Robert J. (1973), "A New Approach to the Economic Theory of Fertility Behavior,' Journal of Political Economy, 81 (March/April), 514-564.

Wright, Peter L. and Frederic Barbour (1977), "Phased Decision Strategies: Sequels to an Initial Screening," in North-Holland/TIMS Studies in the Management Sciences, Vol. 6, eds. Martin K. Starr and Milan Zeleny, Amsterdam: North-Holland. 